\title{
Iron Deposits in the Human Labial Minor Salivary Glands: a Postmortem Study
}

\author{
Yasunori TAKEDA and Hirotsugu YAMAMOTO* \\ (Received 21 November 1988 and accepted 11 January 1989)
}

Key words: iron deposit,. hemosiderin granules, minor salivary gland, postmortem subject

\begin{abstract}
Iron deposits in the human labial minor salivary glands were examined in a series of 195 postmortem subjects. Iron deposits (hemosiderin granules) were found in 7 subjects (3.6\%), and the major types of illness in these cases were liver cirrhosis with or without hepatoma, aplastic anemia and acute myelogenous leukemia. Three out of 7 subjects had a history of blood transfusion. Considerable quantities of hemosiderin granules were deposited wihin the cytoplasm of the acinar and ductal epithelial cells, and hemosiderin-laden cells were scattered in the interstitial connective tissue.
\end{abstract}

\section{Introduction}

Widespread deposits of iron in parenchymal cells of various tissues and organs with or without functional insufficiency of the involved tissues (generalized hemosiderosis or hemochromatosis) may be either idiopathic or caused by genetic disorders, dietary factors, repeated blood transfusion, or iron administration. It is well known that the most common organs showing iron deposits in iron-overload states are the liver, skin, joints, heart, and endocrine glands. As a result, considerable damage may be inflicted on these organs, e. g., liver cirrhosis, skin pigmentation, arthropathy, heart failure and endocrinopathies ${ }^{[1,2]}$. Several case reports have described generalized iron-overload states and the histology of salivary glands ${ }^{[3-8]}$. There are, however, no available reports on the incidence of iron deposits in the salivary glands in various diseases due to iron-overload states.

The present study was carried out to investigate the incidence of iron deposits in human minor salivary glands from autopsy subjects.

\section{Materials and Methods}

Postmortem labial minor salivary glands were obtained from 195 postmortem subjects unaffected by tumors of the head and neck, or by local hemorrhagic or local infectious diseases. The causes of death in these 195 subjects included malignant neoplasms, liver cirrhosis, hepatitis, renal failure, cardiovascular dis-

武田泰典、山本浩嗣*：Department of Oral Pathology, School of Dentistry, Iwate Medical University, 19-1, Uchimaru, Morioka 020, Japan.

* Department of Oral Pathology, Nihon University School of Dentistry at Matsudo. 
eases, bleeding of the gastrointestinal tract, metabolic disturbance, diseases of the hemopoietic system, and senility. Table 1 shows the age and sex distributions of the 195 subjects. Several minor salivary glands of the lower lip were taken from each of the autopsied subjects. The specimens were fixed in $10 \%$ neutral-buffered formalin and embedded in paraffin. Serial sections $5 \mu \mathrm{m}$ thick stained with hematoxylin-eosin and Berlin blue were prepared for microscopic examination.

Table 1 Age and sex distributions of autopsy subjects

\begin{tabular}{ccccccc}
\hline \multirow{2}{*}{ age range $(\mathrm{yr})$} & \multicolumn{3}{c}{ male } & \multicolumn{2}{c}{ female } & \multirow{2}{*}{ total } \\
\cline { 2 - 3 } \cline { 5 - 6 } \cline { 5 - 6 } & number & mean age $(\mathrm{yr})$ & & number & mean age $(\mathrm{yr})$ & \\
\hline-19 & 10 & 17.0 & & 2 & 6.1 & 12 \\
$20-39$ & 22 & 31.3 & & 8 & 27.3 & 30 \\
$40-59$ & 28 & 52.6 & & 25 & 44.7 & 53 \\
$60-79$ & 73 & 68.4 & & 17 & 69.2 & 90 \\
$80-$ & 4 & 84.5 & & 6 & 86.3 & 10 \\
\hline total & 137 & & 58 & & \\
\hline
\end{tabular}

\section{Results}

Iron deposits (hemosiderin granules) in salivary gland epithelial cells were identified in 7 out of 195 subjects, the overall incidence being 3.6\%. Age, sex, main autopsy diagnoses, and direct causes of death of these 7 subjects are shown in Table 2. The main autopsy diagnoses of these 7 subjects were 5 cases of liver cirrhosis with or without hepatoma (cases 3-7), 1 case of aplastic anemia (case 1), and 1 case of acute myelogenous leukemia (case 2). Three subjects had a history of blood transfusion (cases 1, 2, 5).

Table 2 Autopsy cases showing iron deposits in the labial salivary gland

\begin{tabular}{|c|c|c|c|c|c|}
\hline cases & age (yr) & $\operatorname{sex}$ & main autopsy diagnosis & $\begin{array}{l}\text { direct cause of } \\
\text { death }\end{array}$ & $\begin{array}{l}\text { history of blood } \\
\text { transfusion }\end{array}$ \\
\hline case 1 & 28 & $\mathrm{~m}$ & aplastic anemia & heart failure & $11 \times 10^{4} \mathrm{ml}$ \\
\hline case 2 & 35 & $\mathrm{~m}$ & acute myelegenous leukemia & fungus infection & $3,600 \mathrm{ml}$ \\
\hline case 3 & 56 & $\mathrm{~m}$ & liver cirrhosis (posthepatitic) & rupture of varix & \\
\hline case 4 & 61 & $\mathrm{~m}$ & liver cirrhosis (postnecrotic) & hepatic coma & \\
\hline case 5 & 64 & $\mathrm{~m}$ & liver cirrhosis (posthepatitic) & hepatic coma & $1,200 \mathrm{ml}$ \\
\hline case 6 & 66 & $\mathrm{~m}$ & liver cirrhosis (fatty) & heart failure & \\
\hline case 7 & 74 & f & $\begin{array}{l}\text { liver cirrhosis (posthepatitic) } \\
\text { and hepatoma }\end{array}$ & pneumonia & \\
\hline
\end{tabular}

The seven subjects with iron deposits in the salivary glands also showed prominent deposition of iron in the liver and spleen. Unfortunately, information about laboratory values of serum iron, serum ferritin and transferrin saturation before death could not be obtained from the clinical records.

Histologically, iron deposits (hemosiderin granules) were found in both mucous acinar and epithelial cells of intralobular and striated ducts (Figs. 1 \& 2), but were more frequent in the acinar cells. Iron deposits were seen in the basal cytoplasm of the acinar cells (Fig. 1) and in the supranuclear cytoplasm of the ductal epithelial cells (Fig. 2). Occasionally, salivary plugs with iron deposits were 
seen in the ductal lumina (Fig. 3). Salivary glands with iron deposits showed a normal structure or only slight atrophic changes. The hemosiderin-laden cells were scattered in the interstitial connective tissue of some lobules showing atrophic changes (Fig. 4).

\section{Discussion}

Deposition of iron in parencymal cells is divided into the following two types according to pathogenesis; both are similar iron-overload states. The first type is due to a defect in the handling of iron by the reticuloendothelial system, so that early in the course of the disease, iron is deposited in the parenchymal cells of many tissues, or there is generalized dysfunction of iron metabolism involving many tissues, resulting in widespread iron accumulation (primary hemochromatosis). The second type seems primarily to involve saturation of the reticuloendothelial system by iron. The iron may then overflow from the reticuloendothelial system and become deposited in the parenchyma of various tissues (secondary hemochromatosis or generalized hemosiderosis). Commonly involved organs in iron-overload states are the liver, spleen, skin, heart, pancreas and thyroid. In the oral region, the mucous membrane shows hyperpigmentation in $15-25 \%$ of all patients with hemochromatosis, and microscopically there is also an increase of epithelial melanin ${ }^{[9]}$. In addition, approximately half of such patients show iron deposition in sudepithelial macrophages ${ }^{[9]}$.

Only 6 cases of salivary gland involvement in iron overload have been documented $^{[3-8]}$. Of these, a symptom of xerostomia caused by salivary gland dysfunction was proved clinically in 4 cases $^{[3,4,7,8]}$. These authors claimed that if xerostomia is noted in patients with iron-overload states, minor salivary gland biopsy specimens stained with Berlin blue are useful for the establishment of a differential diagnosis between iron overload-related symptoms and other sicca syndromes $^{[3,4,7,8]}$.

In the present study, iron deposits (hemosiderin granules) in minor salivary gland parenchyma were found in 7 out of 195 postmortem cases. Since prominent deposition of iron was seen in the liver and spleen of all 7 cases, it can be assumed that these patients had been in an iron-overload state before death, although laboratory data on serum iron, ferritin and transferrin saturation before death could not be obtained from the clinical records. Of these 7 patients, 5 had been suffering from liver cirrhosis with or without hepatoma. It is well known that iron deposits are frequently seen in hepatocytes and reticuloendothelial cells in patients with liver cirrhosis, and it has been reported that many persons with cirrhosis absorb more iron than normal ${ }^{[10,11]}$, although there is no correlation between the amount or concentration of iron, and the presence or degree of liver cirrhosis ${ }^{[12]}$.

In conclusion, these results suggest that iron is deposited occasionally in salivary gland epithelial cells under iron-overload conditions, and that in some cases of severe iron overload, the patient may develop sicca symptoms, since iron is known to have deleterious effects on the parenchymal cells of various tissues. 


\section{References}

[1] Scarpelli, D. G. and Chiga, M.: Cell injury and errors of metabolism. In Anderson's Pathology, Vol. 1, 8th ed., 83, Kissane, J. M. Ed., C. V. Mosby Co., St. Louis, 1985

[2] W Edinburgh, London and New York, 1979

[3] Blandford, R. L., Dowdle, J. R., Stephens, M. R. and W associated with idiopathic haemochromatosis, Brit. Med. J., 283, 1323,1979

[4] Borgna-Pignatti, C., Cammareri, V., DE Stefano, P. and Magrini, U. : The sicca syndrome in thalassemia major. Brit. Med. J., 288, 668-669. 1984

[5] DeAN, D. H. and Hiramoto, R. N.: Submandibular salivary gland involvement in hemochromatosis, J. Oral Med., 39, 197-198, 1984

[6] Frantzis, T. G., Sheridan, P. J., Reeve, C. M. and Young, L. L.: Oral manifestation of hemochromatosis: Report of a case, Oral Surg. 33, 186-190, 1972

[7] TAKEDA, Y. and OHYA, T.: Sicca symptom in patient with hemochromatosis: minor salivary gland biopsy for differential diagnosis, Int. J. Oral Maxillofac. Surg., 16, 745-749, 1987

[8] Ward-Booth, P., Ferguson, M. M. and Macdonald, D. G.: Salivary gland involvement in hemochromatosis, Oral Surg., 51, 487-488, 1981

[9] Mescon, H., Grots, I. A. and Gorlin, R. J.: Mucocutaneous disorders. In Thoma's Oral Pathology, Vol. 2, 6th ed., 673, Gorlin, R. J. and Goldman, H. M., Eds., C. V. Mosby Co., St. Louis, 1970

[10] Conrad, M. E. JR., Berman, A. and Crosby, W. H.: Iron kinetics in Laennec's cirrhosis, Gastroenterol., 43, 385-390, 1962

[11] Deller, D. J.: Iron ${ }^{59}$ absorption measurements by whole-body counting: studies in alcoholic cirrhosis, hemochromatosis, and pancreatitis, Amer. J. Dig. Dis., 10, 249-258, 1965

[12] Macdonald, R. A.: Tissue iron and hemochromatosis: comparative study in Denver and Boston, Arch. Path., 84, 543-551, 1967 

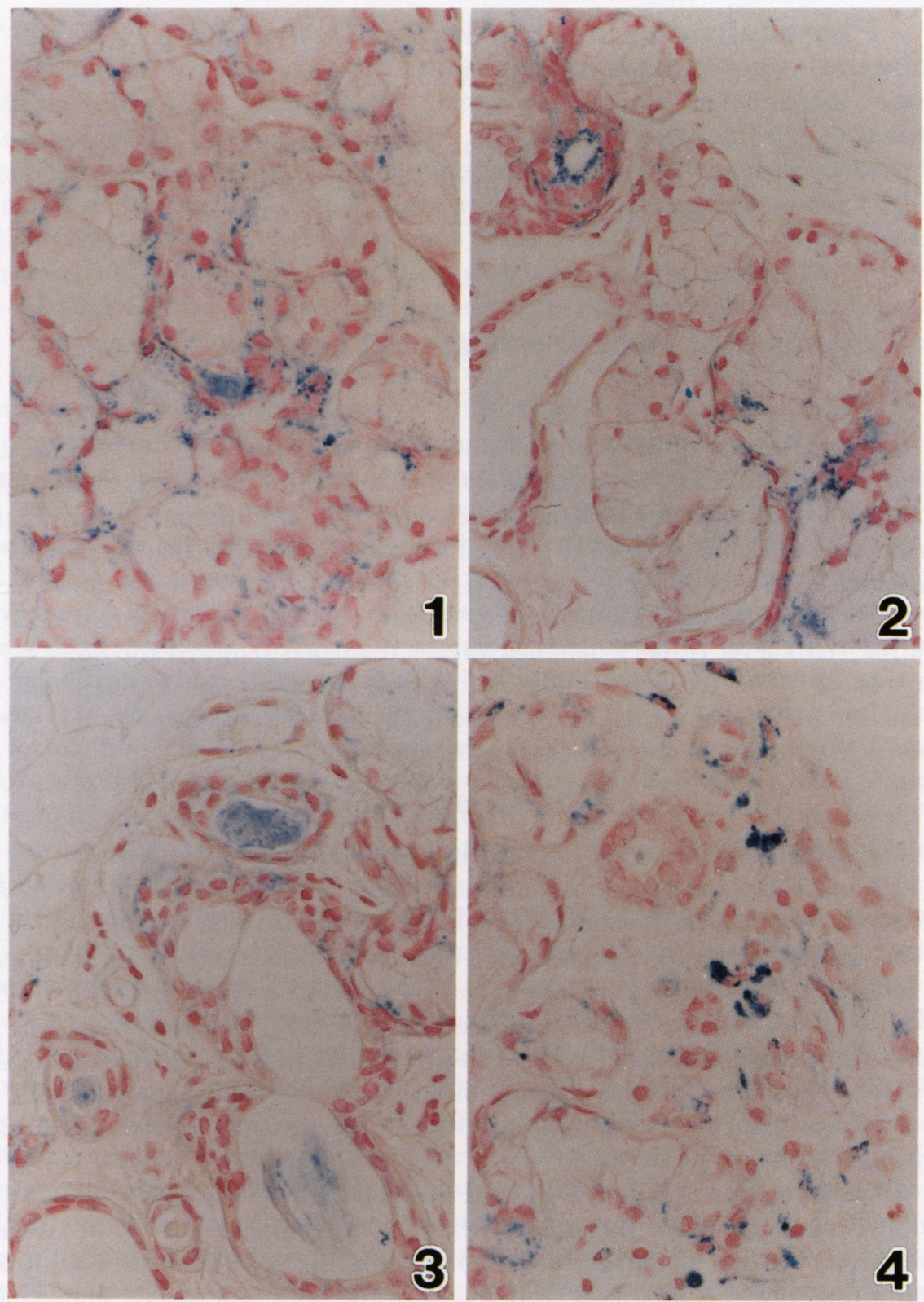

Figs. 1-4. Iron deposits (hemosiderin granules) in the mucous acinar cells (1) and ductal epithelial cells (2) of labial minor salivary glands. Iron is deposited in the basal area of the acinar cells (1) and in the supranuclear area of the ductal epithelial cells (2). Salivary plugs containing iron are evident in the ductal lumen with or without dilatation (3). Hemosiderin-laden cells are scattered in the interstitial tissue of some lobules showing atrophic change (4). (Berlin blue stain: x300). 